\title{
DISCOVERY OF A POTENTIAL SITE FOR COMMUNITY-BASED SUSTAINABLE ECOTOURISM IN THE SUNDARBANS RESERVE FORESTS, BANGLADESH
}

\author{
Mohammad Zahirul Haque \\ School of Environmental and Natural Resources Sciences \\ Faculty of Science and Technology \\ Universiti Kebangsaan Malaysia \\ 43600 Bangi, Selangor, Malaysia \\ and \\ Bangladesh Forest Department \\ Bono Bhaban, Agargaon \\ Dhaka 1207, Bangladesh \\ Email: zahirfd@yahoo.co.uk \\ Mohammad Imam Hasan Reza \\ Institute for Environment and Development (LESTARI) \\ Universiti Kebangsaan Malaysia \\ 43600 Bangi, Selangor, Malaysia \\ Email: rezamih@gmail.com \\ Md. Mahmudul Alam \\ Senior Lecturer \\ School of Economics, Finance \& Banking (SEFB) \\ College of Business (COB) \\ Universiti Utara Malaysia (UUM) \\ 06010 UUM Sintok, Kedah, Malaysia \\ Email: rony000@gmail.com \\ Zahir Uddin Ahmed \\ Bangladesh Forest Department \\ Bono Bhaban, Agargaon \\ Dhaka 1207, Bangladesh. \\ Email: zahirfd84@yahoo.com \\ Md. Wasiul Islam \\ Forestry and Wood Technology Discipline \\ Khulna University \\ Khulna, Bangladesh \\ Email: wasiulislam7@yahoo.com
}

\section{Citation Reference:}

Haque, M.Z., Reza, M.I.H., Alam, M.M., Ahmed, Z.U., and Islam, M.W. 2016. Discovery of a Potential Site for Community-based Sustainable Ecotourism in the Sundarbans Reserve Forests, Bangladesh. International Journal of Conservation Science, 7(2): 553566. http://www.ijcs.uaic.ro/public/lJCS-16-30 Haque.pdf

This is a pre-publication copy.

The published article is copyrighted by the publisher of the journal. 


\title{
DISCOVERY OF A POTENTIAL SITE FOR COMMUNITY-BASED SUSTAINABLE ECOTOURISM IN THE SUNDARBANS RESERVE FORESTS, BANGLADESH
}

\begin{abstract}
Conservation of biological diversity is a pressing need and protected areas are the cornerstones for conserving remaining flora and fauna. However, forest dependent livelihood in countries like Bangladesh making this task very critical. In the case of the poor and forest-dependent livelihood in the Sundarbans area of Bangladesh, an eco-friendly ecotourism may provide an alternative livelihood, which may reduce the overexploitation from the valuable Sundarbans forest ecosystems. Furthermore, this initiative may also serve to aware people on the value of this unique ecosystems. Therefore, this study discusses the scope, benefits and challenges for developing sustainable ecotourism within the protected area. It focuses on the development of a potential site for sustainable ecotourism inside the Sundarbans Reserve Forest. Developing sustainable tourism spots inside the wildlife hub has a high demand among tourists and it is also necessary for the socio-economic development of the local community, moreover, the approach of community-based ecotourism (CBEM) is a suitable strategy for conservation of protected areas.
\end{abstract}

Keywords: Community Based Ecotourism (CBEM); biodiversity conservation; sustainability; site development; protected area

\section{Introduction}

The Sundarbans Reserve Forests (SRF), which is the largest mangrove ecosystem in the world, is one of the protected areas in Bangladesh (Biswas et al., 2007; Das and Siddiqi, 1985; Gopal and Chauhan, 2006). Its beauty lies in its unique natural surroundings. Thousands of meandering streams, creeks, rivers and estuaries have enhanced its charm (Manna et al., 2010). It is the natural habitat of the world famous royal Bengal tiger, spotted deer, crocodiles, jungle fowl, wild boar, lizards, monkeys and an innumerable variety of beautiful birds (Islam and Gnauck, 2009). Flocks of flying migratory Siberian ducks, sail boats loaded with Golpata (Nipa fruticans), honey, shell and fish further add to the serene natural beauty of the SRF. There is ample potential for ecotourism spots in the SRF where each one may have special significant characteristics.

The scenario of the mangrove plants, the basking of crocodiles along the margin of the creeks and inlets and transforming of the water body into a bird sanctuary by the thousands of migratory birds and colorful ducks in the winter, the sharp movements of the spotted deer at the waterholes and seashore, the soft bird calls, and the sudden meeting of flagship species- the Royal Bengal Tiger, will certainly touch the heart of both the native and overseas tourists (Salam et al., 2000).

Tourism is a popular global leisure activity, which has large economic value for many countries, especially in the developing world. Tourism offers opportunities for substantial growth, although success depends on effective marketplace value, quality of the products developed and the establishment of meaningful community-private-public partnerships (UNWTO 2004). Nowadays environment friendly as well as knowledge-orientated tourism such 
as ecotourism, adventure tourism, and cultural tourism has excellent prospects worldwide with improving educational levels where the tourists are known for their modest expectations in terms of facilities, amenities, service, and comfort. Ecotourism is typically defined as travel to destinations where flora, fauna, and cultural heritage are the primary attractions (Ross and Wall, 1999). Protected areas are commonly utilized for the purpose of ecotourism where the natural capital (e.g., landscapes, flora, fauna, etc.) and associated traditional cultures of the protected areas are the major attractions for the tourists (Ceballos-Lascurain et al., 1993; Walpole and Goodwin, 2001).

Developing the ecotourism sites in the SRF will be a great opportunity for earning among the local community, especially for the pro-poor group who are dependent on the natural resources. That will also help to reduce the over exploitation of the natural resources by local community (Iftekhar and Islam, 2004). The resources of the SRF have great potential to encourage and develop community based ecotourism in the villages located at the vicinity of the forest that have direct interests on the forest (Banerjee). In turn, the natural and environmental importance of this venue will attract many local and international tourists (Assaker et al., 2014). The local poor people can be engaged in different activities, which enable them to earn money and to build environmental awareness to promote the conservation of natural resources.

Community-based tourism (CBT) is a visitor-host interaction in a win-win situation that has meaningful participation by both the visitor and the host (Wimalaratana and Silva, 2009), and generates economic and conservation benefits for local communities and the environment (Vajirakachorn, 2011). CBT is an emerging activity that is generating a lot of interest among the local people, tour operators, government agencies, and the business sector (Jain and Triraganon, 2003). Advocates of participatory conservation approaches insist that by denying local people access to protected areas (Shackelton et al., 2002) and by excluding them from decision-making processes, conservationists create tension between park managers and local residents, increase monitoring costs, and fail to benefit from the valuable local knowledge and resource management systems (Agrawal and Gibson, 1999; Berkes, 1989; Salam et al., 2000; Sponsel et al., 1996; Wells and Bradon, 1992; Western et al.). Moreover, communities are now the locus of the conservationist thinking Promoting tourism to existing protected areas (Eagles et al., 2002) and sharing a part of the profit with communities is a popular community-based conservation strategy This can be done by encouraging or facilitating local investment into tourism activities (Western et al., 1993) .

Further, promoting ecotourism has also been emphasized by the World Bank (2011) for Strengthening Regional Cooperation for Wildlife Protection in Asia (SRCWP) Project (World Bank, 2011) Therefore, this study is an attempt to assess the feasibility of developing community-based sustainable ecotourism in a potential site, locally known as the Shekher Khal, which is inside the protected area and has both ecological and archaeological values.

\section{Importance and Description of the Site}

\subsection{Location of the Area}

The site of the Shekher Khal (canal of Shekh) is situated near the Adachai Patrol Post under the Khulna Range of Sundarbans West Forest Division in Bangladesh. In this area, a few ancient ruined buildings still exist which inspires the modern adventure-loving tourists to know more 
about the significance and mysterious past of the area. Some of these ancient building structures are the Shekher Bari (house of Shekh), Kalir Khal Mandir (temple of Kali canal), Beder Bari (house of gipsy community), Khutir khal iter paza (Khutir canal brick fields), etc.

The geographical location of one point of the temple is N22 ${ }^{\circ} 13.253^{\prime}$, E $89^{0} 29.922^{\prime}$ and

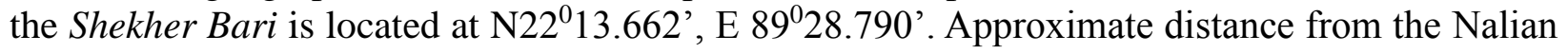
Forest Range Headquarters and the Adachai Forest Office (Patrol Post) to the Shekher Bari is about $26 \mathrm{~km}$ and $5 \mathrm{~km}$ respectively, and the distance from the Shekher Bari to the Kalir Khal Mandir is about $2 \mathrm{~km}$ within the site.

The total ecotourism center has 2 units - one unit is the Shekher Bari with an area of 0.54 $\mathrm{km}^{2}$ and the other one is the Kalir Khal Mandir with an area of $0.67 \mathrm{~km}^{2}$. The natural features of the area consist of rivers and forests. The forests are of low storied forest $(\sim 54 \%)$ and high storied forests ( 46\%). The Shekher Bari is on the bank of the Shekher Khal which is close to the vast river Shibsa, and the Kalir Khal Mandir is on the bank of the Kalir Khal. The location of the full site is prepared by the authors using GIS tools (Figure 1).

Figure 1: Location of the site - Shekher Khal

Source: Drawn by authors

The source of the map is obtained from Google earth. It is then given georeference coordinates and made digitized by Arc GIS 9.3 software. The map shows various features with their area of the site such as high and low storied forests, river, ancient building and local forest office stated inTable1. Each of the features was identified with different color.

Table 1: Feature with area of the study area

The environmental position of the site is low (below 20m) relief (difference in elevation) and upper and medium (30-40\%) slope of land. The soil type is clay, and depth of top soil is shallow $(<20 \mathrm{~cm})$. Soil erosion is low. The land is dry on average for only five months per year. The climate is wet. There is no source of fresh surface water. The ground water is available by digging well but the quality of that water is poor. The area is affected by natural disasters such as cyclones, tidal waves, storms, etc. and geological hazards such as landslides.

\subsection{Historical and Archaeological Values of the Area}

The Sheikher Khal ancient ruined structures are historically and culturally interesting and appealing to the modern tourists. Thus, this is the only location inside the SRF of Bangladesh where man-made ancient structures have been discovered. The site consists of relics of temples, houses, ponds, etc.

According to the information derived from the local people, Muslim and Hindu communities lived in the area; the Shekh community was Muslim in religion so they lived separately beside the Shibsa river bank and the Hindu community lived near the temple and its surroundings beside the Kalir Khal. The houses of the Shekh community are found on the east bank of the river Shibsa, the destroyed residue of which are visible from this river bank. Though the local people generally call the site the Shekher Mandir, in actual fact, the temple is the Kalir 
Mandir. There are evidences which explain that a ruined building beside the Kalir Mandir has been identified and proclaimed as the Hindu Zamindar Bari (house of landlord), and the temple was constructed by that Zamindar.

The Sheikh community lived separately a little far away from the Hindu community. The Shekher Bari site lies on the forest floor adjacent to the river bank of Shibsa and the temple is approximately $1.0 \mathrm{~km}$ away from the bank of the nearest Shekher Khal canal. Both the sites are disconnected with trawler/ boat stoppage points, which may be troublesome for tourists to reach the spot. There is neither footpath or trail nor any sign or indication to follow to reach the temple or the Shekher Bari at present.

It is assumed that some Bede (gipsy community) people lived beside the Beder Khal. In this clutch of land on the other side (west bank) of the river Shibsa and near the Khutir Khal, a ruined relic of brick field (locally known as the Iter Paja) had been discovered by the fishermen. It is believed that the building materials used for construction of these ancient buildings were mainly supplied from this brick field and were used as the masonries of small thin bricks, lime and brick powder.

Figure 2: The entrance point of the ancient Kalir Mandir and the design of the ancient bricks Source: Photo taken by authors

There is no specific record of the age of these structures but it is assumed that these ancient structures were built about 400 years ago (Figure 2) when Saint Hazrat Khan Jahan Ali (R) came to Jessore and started clearing up the forest land and converted it into paddy fields and later proceeded up to the Khulna and Bagerhat district. It is also believed that these establishments might have existed before his arrival into this region.

However, there is no accurate evidence of settlement and construction period for these buildings and for the origins of the people who came to settle down there. Information received from the local people suggests that based on an assumption, due to severe natural calamities near Java or Sumatra Island, the inhabitants of those areas were compelled to migrate to Sundarbans. Some aboriginal people called the 'Kapali' at present, living in Jorsing under the area of the Koyra police station of Khulna district are said to be their descendant. Another opinion of the local people is that the miscreants or pyrites inside these forests had been ransomed nearly 600 years ago.

\subsection{Ecological Value of the Area}

The archaeological structures of the site are situated inside the dense virgin forests of mixed mangrove species dominated by Sundri (Heritiera fomes). The site is rich with a unique biodiversity. The major species of plants that keep these relics hidden inside the forests are Pasur (Xylocarpus mekongensis), Bain (Avicennia officinalis), Gewa (Excoecaria agallocha), Goran (Ceriops decandra), Golpatta (Nypa fruticans), etc. with some rarely found orchids and climbers. Both sides of the Shekher canal bank from the river Shibsa up to the temple side are fenced densely by natural Hental plants (Phoenix paludosa) that provide extra scenic beauty to this area (Figure 3). 
Figure 3: Shekher Bari on the bank of the river Shibsa and the Shekher Khal Source: Photo taken by authors

Furthermore, the Royal Bengal Tiger is very frequently visible at this site. We captured recent pug marks of a number of tigers around the temple site (Figure 4) with other animals such as the deer, wild boars, monkeys, monitor lizards, snakes, otters, etc. Many arboreal species and birds such as the jungle fowl, brown-winged kingfishers, lesser adjutants (Leptoptilos javanicus), grey-headed fish eagles (Ichthyophaga ichthyaetus), open billed storks, coots, pheasant-tailed jacanas, Brahminy kites, gray herons, great egrets, , cormorants, common kingfishers, masked fin-foot, and owls. Approximately 13.35 square kilometers of water body in this location that includes canals and creeks are abundant with many species of fishes and other aquatic species.

Figure 4: Pug marks of a couple of tigers at the temple site and pug marks while chasing preys Source: Photo taken by authors

Moreover, there are some non-mangrove species such as Gaab (Diospyros sp.), Bot (Ficus sp.), Bhui kumari (local name of a climber), etc. found at the site, which evidences the descendant of the pioneer ones planted by the then inhabitants. The answer to the questions of how these species are found at these sites is that the inhabitants' livelihood was totally boatbased and there were no easy facilities to repair their boats from any nearby location. Perhaps they used this $G a b$ fruits to repair the boats. Moreover, its fruit is also delicious to eat. Likewise, the Bhuikumari was also edible to them and they planted the ficus species probably for their worship.

\subsection{Tourism Potential}

According to the average of last 7 years' records of the Bangladesh Forest Department, about 22000 local and 294 foreign tourists visit the Sundarbans west forest division every year. Within these years this number was highest in the year 2011-2012 with the figure 42805 local and 747 foreign tourists (Table 2). The number of tourists increase from October to April or May due to the calm river conditions during that part of the year. The existing beautiful spots to visit in this division are Kalatali, Munshiganj, the Nilkamal world heritage site, and the Dublar Char, although administratively, Dublar Char falls under the Sundarbans East Forest Division. A majority of tourists use the route through the Sundarbans West Forest Division to visit that place mainly in November when the Rash Purnimar Mela occurs - a worship festival of the Hindu community. The site of Shekher Khal is situated in the Sundarbans West Forest Division and halfway through the Nilkamal or Dublar char. Therefore, it is predicted that these tourists will visit this site. Besides, the intangible environmental benefit, which the tourists enjoy, must be several times more than this earning.

Table 2: Number of visitors to the Sundarbans West Forest Division

\section{Ensuring Sustainable Ecotourism}

\subsection{Sustainable Activities of Tourists}

The site is situated approximately $15 \mathrm{~km}$ away from the nearest periphery of the forest and the participants need to pass through a long distance inside the forests. Moreover, massive participation and sharing of local people and NGOs may create chances to disturb the serene 
habitat of the wildlife and frequent pollution of water body and land mass and may also raise the apprehension of poaching of wildlife and other valuable natural resources (Alam et al., 2009; Salam et al., 2000). Therefore, engagement of a minimum number of people for the service must be considered.

It is proposed that tourists arrive at the Nalian Forest Range Headquarter and collect the permits before they go for site visiting. The journey starts by engine boat from Nalian Forest Range Headquarter to Shekher Bari with an eco-guide and forest guards for security purposes. After visiting the Shekher Bari, they will visit the temple site by dingi (small) boat through canals. A watch tower will support them to observe the total area of the site. The duration of visit will follow the high and low tide of the rivers and tourists will not be allowed to stay overnight there.

Nalian and some nearby places such as Kashiabad, Hodda and Kalabogi will be developed with various permanent and temporary infrastructures such as eco-cottage, shopping market consisting of local and traditional goods, museum, cultural center, display centers, and restaurants for local and traditional foods in participation with the local people and various government and non-governmental organizations. These attractive facilities will be availed to the tourists while they wait for their destination. Management components such as eco-cottage proprietors, eco-guides, tour operators and trawler owners will perform their best to serve the tourists at this stage.

\subsection{Archaeological and Ecological Sustainability}

At present, the archaeological structures in the site are being destroyed. The preservation of these structures is very urgent. The combined archaeological and ecological features create a strong value of tourism in this site (Wallace and Russell, 2004). Moreover, preserving the archaeological structures or developing tourism in this site will also contribute towards ecological sustainability in that area by turning the local people from direct dependency on the forest resources (Iqball et al., 2010).

The introduction of ecotourism will not accelerate land disturbance in terms of site clearance because no new site will be included for development (Table 3). Therefore, the effects on rare (vulnerable), threatened or endangered species of flora or fauna or their habitat and on designated wetlands is negligible. The management operation in the site will be ensured by the minimum negative effects of spread of invasive plants or animals, disturbance of wildlife habitat, populations, corridors or movement, locally important or valued ecosystems or vegetation, destruction of trees and vegetation and impact on fish migration and navigation.

Table 3: Potential Impacts on Site Environment due to the Development of Ecotourism

The project design reflects no obstruction on natural connections between rivers and wetlands inside the project area or the natural drainage system, water logging due to inadequate drainage, preventing salinity intrusion, surface water quality and quantities or flow, groundwater quality and quantity or movement and sedimentation or soil erosion or shoreline and riverbank erosion on or off site. The tourists' drinking water source is outside of the ecotourism area hence 
increased demand of water requirements leading to reduction of water supply for competing uses is not considered an issue.

Observation is the main activity by the tourists; therefore, direct human contact with biodiversity will be negligible which results in no spread of diseases and parasites in the wilderness. The archaeological aspect is the predominant condition to establish this complex and therefore - loss of existing buildings, property, economic livelihood, soil stability and compactness, impacts on sustainability of associated construction waste disposal and changes to the land due to material extraction will be kept minimized.

Traffic disturbances and increased noise due to transportation of wastes and construction materials and day-to-day construction activities, increased wind-blown dust from material (e.g. fine aggregate) storage areas, degradation or disturbance of historical or culturally important sites and the risks of health and safety problems are temporary issues that will end after the site development activities have been completed. The impact on setting up of ancillary production facilities is low while the impacts on significant demands on utilities and services and the accommodation or service amenities to support the workforce during construction are high and medium, respectively.

\subsection{Socioeconomic Sustainability of Local Community}

The prime challenge of the SRF is the conservation of its natural resources. SRF can be conserved based on various schools of thought (World Bank, 2011). Community based ecotourism (CBET) is such an option from tourism (Kiss, 2004) lens which has immense potentialities to facilitate conservation initiatives of the Sundarbans (Chadha and Onkar, 2014). This type of tourism is a potential at the SRF and its surrounding landscape villages (within $5 \mathrm{~km}$ from the boundary of the SRF) (Islam, 2010). Key issues for the development of CBET are participation, markets and customers, capacity growth, impacts and monitoring, partnerships and collaborations and policies (Jain and Triraganon, 2003). CBET matches the development of the Shekher Khal historic site ecotourism project through its different activities and operations.

The objectives of the CBT and ecotourism cover great potentialities to be developed to emancipate the local people and improve their socio-economic status (RECOFTC, 2007) through the enhancement of the capacity building of the forest department, concerned NGOs and local communities on CBET; alternative income generating (AIG) opportunities for the local inhabitants of the adjacent local communities to make them environmentally aware and educated, which enables them to assist in improving the conservation of natural (biodiversity) and cultural resources in and around the SRF; and establishing and promoting a historical and cultural ecotourism destination for the eco-tourists and also to preserve the cultural heritage of the site.

Local people surrounding the villages of the SRF may play a strong and vital role in the conservation of the natural resources of SRF. They are the most vulnerable population due to different natural calamities like cyclones, tidal waves, storms, landslides, etc. (Hossain et al., 2012) Due to lack of income opportunities, education and environmental consciousness, most of them are fully or partially dependent on the natural resources of the SRF which threatens the forest as a whole (Singh et al., 2010). This scenario urges colossal alternative income generation 
(AIG) opportunities for the locals which can alter the pattern of dependency on the natural resources of the Sundarbans (Islam et al., 2013). This modified dependency on the Sundarbans will contribute to reduce the extraction of natural resources of the forest and restrict their noncooperation attitude to destroy the forest (Islam, 2010).

\subsection{Monitoring the Issue of Sustainability}

Currently, due to the lack of manpower, financial, logistic and other supports to the forest department, forest officials remain under pressure to protect the forest against these miscreants (Singh et al., 2010). Participatory monitoring with the stakeholders for the implementation of the planned activities in relation to the allocated funds and time line and security situation will be checked on from time to time (participatory monitoring) (Muhammed et al., 2005) with the help of different indicators related to tourism and recreation in the proposed area. Participatory evaluation in different stages (pre-ante, ongoing and post-ante) of the project will also facilitate to monitor and evaluate the project activities. The overall status of the natural resources of the site will be assessed by participatory monitoring and evaluation (PME) by the government through the forest department (Islam et al., 2013).

\section{Site Development Activities \\ 4.1 Infrastructural Development}

To facilitate the tourism opportunity, initial infrastructural development will consist of the construction of two jetties and the construction of two elevated wooden walkway from the riverbank to the Shekher Bari and Kalir Mandir. In addition, the construction of 4 resting places at the elevated wooden walk-way, an elevated wooden platform near the temple to take shelter during the high tide, construction of a canopy walk around the site, reconstruction and maintenance of the Mandir and Shekher Bari, different signage and directions at the site and other areas where necessary, and construction of 2 toilets and 2 wash rooms near the temple area would be carried out.

Expected construction period for the above works might be 8 months, and total approximate cost for the same might be approximately BDT 15 million (USD $\$ 0.187 \mathrm{~m}$ ). The initial investment for the site development can be recovered within 5-10 years and the project can be sustained with profits. For an example, if half of the current annual visitors visit this site at the rate of BDT 50 for local and BDT 1000 for foreign tourist, the investment will not take more than 10 years to be recovered. Further, the number of tourists will increase year by year.

\subsection{Capacity Building}

It is the most important aspect next to the infrastructural development to offer mobility to the investment. Capacity building includes activities such as development of a local training center (Korten, 1980) (with existing infrastructure) at the adjacent village of the forest boundary with the aim to train on different aspects of CBET development and promotion for employees of the forest department and NGOs concerned to the local community, etc.

The emphasized aspects of the training will cover the issues of tourism, ecotourism, community-based ecotourism, cultural and heritage tourism, environmental education including formal and informal rules, regulations, norms, bindings, and awareness with particular reference to the Sundarbans. It would also include host-guest relationship in community based ecotourism, 
planning and development of community-based Ecotourism in the Sundarbans, volunteer services in community-based ecotourism, promoting local enterprises, establishing local tour operators in the project area, participatory monitoring and evaluation and involvement of multistakeholders/actors, partnership and collaboration in community based ecotourism, etc.

Several other aspects of capacity building are the preparation of training materials, and educational and experience sharing tours (excursions) for the trainees and trainers at home and abroad. Development of educational and motivational materials (printed, documentary, electronic, etc.) for campaigns, regular discussions and meetings with different stakeholders to develop and promote CBET, development of a website focusing on the activities of this proposed CBET project as well as building awareness and motivation for potential tourists and support to establish a local tour operator would also be included.

\subsection{Community Involvement}

One of the modern concepts to implement the project smoothly with the scopes of job opportunity, interactions among all levels of population, social bindings, and cost benefit sharing and so on, is community involvement (Scheyvens, 1999). This parameter of site development function is formed with awareness and motivation activities, involvement of local community members in different AIG activities (Galley and Clifton, 2004), participatory monitoring and evaluation, redesigning or modification of this project based on lessons and learning from the participatory monitoring and evaluation, and partnerships and collaborations between the local communities and different relevant stakeholders/actors. It would involve the arrangement of two annual cultural and heritage fairs at the adjacent villages and observations of Global Tiger Day (29 July), International Tourism Day (27 Sept), World Environmental Day (5 June), World Wetland Day (2 February), International Mangrove Day (26 July), and Sundarbans Day (14 Feb), to create awareness and motivation among the local community and other concerned people of different relevant organizations and the promotion and marketing of CBET and its various services and products.

\section{Conclusions}

This study attempted to assess the development of community-based sustainable ecotourism at the Shekher Khal area in the Sundarbans Reserve Forests. Ecologically, this site is very interesting because of its location inside the reserve forest and its high natural beauty. Archaeologically, these are the only man-made ancient structures found inside the SRF of Bangladesh, an area established by both the Hindus and Muslims. These mysterious and fascinating temples and other structures will raise many questions and curiosities among the tourists. Besides tourists, the area would also be interesting and intriguing for religious people. Therefore, the archaeological preservation of this site is very important. At the same time, the site has strong potential for development of ecotourism activities.

After considering the overall assessment and potentiality of this site, this study proposes to develop and promote the Shekher Khal area as an important tourist destination in the SRF through an innovative and alternative eco-friendly tourism approach. On the one hand, these opportunities will make money for the local people and on the other hand, these people or even the entire community will be environmentally aware and motivated to conserve the natural resources of the SRF. Using this way is also expected to discourage illegal trespassing inside the 
SRF. By serving these diversified benefits through the CBET, particularly based on the concerned issues, this development will preserve the archaeological ancient structures and facilitate wildlife habitat restoration and protection of the Sundarbans mangrove forest as well. This study will help the respective agencies to take initiatives in the development of this site.

\section{Acknowledgment}

Two university research projects- DLP-2014-015 and GUP-2014-042 of Universiti Kebangsaan Malaysia (UKM) are gratefully acknowledged for supporting this research. Bangladesh Forest Department, Bangladesh and Forestry and Wood Technology Discipline, Khulna University, Khulna, Bangladesh are also acknowledged for providing valuable information for this study.

\section{References}

Agrawal, A., Gibson, C.C., 1999. Enchantment and disenchantment: the role of community in natural resource conservation. World development 27, 629-649.

Alam, M., Furukawa, Y., Akter, S., 2009. "Forest-based Tourism in Bangladesh: Status, Problems and Prospects".163-172

Assaker, G., Hallak, R., Vinzi, V.E., O’Connor, P. 2014. An empirical operationalization of countries destination comperativeness using Partial Least Squares Modeling, Journal of Travel Research 53(1), 26-43.

Banerjee, M.,2014. ECO Tourism in Sunderbans... A Life Line For Local People and the Ecology. International Journal of Science and Research 3 (2), 761-771.

Berkes, F., 1989. Common property resources: ecology and community-based sustainable development. Belhaven Press.

Biswas, S.R., Choudhury, J.K., Nishat, A., Rahman, M.M., 2007. Do invasive plants threaten the Sundarbans mangrove forest of Bangladesh? Forest Ecology and Management 245, 1-9.

Ceballos-Lascurain, H., Lindberg, K., Hawkins, D., 1993. "Ecotourism as a worldwide phenomenon". In: Lindberg, K. and Hawkins, D. (eds) Ecotourism: a Guide for Planners and Managers. Ecotourism Society, North Bennington, Vermont, pp. 12-14

Chadha, H., Onkar, P., 2014. Community Participation: An Approach towards Inclusive Tourism Development in India, ISCONTOUR 2014-Tourism Research Perspectives: Proceedings of the International Student Conference in Tourism Research. p. 281.

Das, S., Siddiqi, N., 1985. The mangroves and mangrove forests of Bangladesh. BulletinBangladesh Forest Research Institute. Mangrove Silviculture Division (Bangladesh). No 2.

Eagles, P.F., McCool, S.F., Haynes, C.D., Phillips, A., Programme, U.N.E., 2002. Sustainable tourism in protected areas: Guidelines for planning and management. IUCN Gland, Switzerland and Cambridge, UK.

Galley, G., Clifton, J., 2004. The motivational and demographic characteristics of research ecotourists: Operation Wallacea volunteers in Southeast Sulawesi, Indonesia. Journal of Ecotourism 3, 69-82.

Gopal, B., Chauhan, M., 2006. Biodiversity and its conservation in the Sundarban Mangrove Ecosystem. Aquatic Sciences 68, 338-354.

Hossain, M.A., Reza, M.I., Rahman, S., Kayes, I., 2012. "Climate change and its impacts on the livelihoods of the vulnerable people in the southwestern coastal zone in Bangladesh". In Climate change and the sustainable use of water resources. pp. 237-259, Springer Berlin Heidelberg. 
Iftekhar, M., Islam, M., 2004. Managing mangroves in Bangladesh: A strategy analysis. Journal of Coastal Conservation 10, 139-146.

Iqball, M., Salequzzaman, M., Haque, S., Islam, M., Ahmed, M., 2010. Ecotourism in the Sundarbans and its surrounding-a possible sustainable option for alternative livelihood development. Bangladesh Research Publications Journal 4, 244-253.

Islam, M.S.N., Gnauck, A., 2009. Threats to the Sundarbans mangrove wetland ecosystems from transboundary water allocation in the Ganges basin: A preliminary problem analysis. International Journal of Ecological Economics and Statistics, 13, 64-78.

Islam, M.W., Rahman, M.M., Iftekhar, M.S., Rakkibu, M.G., 2013. Can community-based tourism facilitate conservation of the Bangladesh Sundarbans? Journal of Ecotourism 12, 119-129.

Jain, N., Triraganon, R., 2003. Community-based tourism for conservation and development: A training manual. Washington, DC, and Bangkok, Thailand: The Mountain Institute and RECOFTC

Kiss, A., 2004. Is community-based ecotourism a good use of biodiversity conservation funds? Trends in Ecology \& Evolution 19, 232-237.

Korten, D.C., 1980. Community organization and rural development: A learning process approach. Public administration review 40 (5), 480-511.

Manna, S., Chaudhuri, K., Bhattacharyya, S., Bhattacharyya, M., 2010. Dynamics of Sundarban estuarine ecosystem: eutrophication induced threat to mangroves. Saline systems 6 (1), article 8.

Muhammed, N., Koike, M., Sajjaduzzaman, M., Sophanarith, K., 2005. Reckoning social forestry in Bangladesh: policy and plan versus implementation. Forestry 78, 373-383.

Ross, S., Wall, G., 1999. Ecotourism: towards congruence between theory and practice. Tourism Management 20, 123-132.

Salam, M.A., LINDSAY, G.R., BEVERIDGE, M.C., 2000. Eco-tourism to protect the reserve mangrove forest the Sundarbans and its flora and fauna. Anatolia 11, 56-66.

Scheyvens, R., 1999. Ecotourism and the empowerment of local communities. Tourism Management 20, 245-249.

Shackelton, S., Campbell, B., Wollenberg, E., Edmunds, D., 2002. "Devolution and communitybased natural resource management: creating space for local people to participate and benefit". ODI Natural Perspectives 76.

Singh, A., Bhattacharya, P., Vyas, P., Roy, S., 2010. Contribution of NTFPs in the livelihood of mangrove forest dwellers of Sundarban. Journal of Human Ecology 29, 191.

Sponsel, L.E., Headland, T.N., Bailey, R.C., 1996. Tropical deforestation: the human dimension. Columbia University Press.

Vajirakachorn, T., 2011. Determinants of success for community-based tourism: The case of floating markets in Thailand. Texas A\&M University.

Wallace, G., Russell, A., 2004. Eco-cultural tourism as a means for the sustainable development of culturally marginal and environmentally sensitive regions. Tourist Studies 4, 235-254.

Walpole, M.J., Goodwin, H.J., 2001. Local attitudes towards conservation and tourism around Komodo National Park, Indonesia. Environmental Conservation 28, 160-166.

Wells, M., Bradon, K., 1992. People and parks: linking protected area management with local communities. World Bank.

Western, D., Lindberg, K., Hawkins, D., 1993. "Defining ecotourism”. In K. Lindbergh and D.E. Hawkins (eds) Ecotourism: A Guide for Planners and Managers, 7-11. 
Western, D., Wright, R., Strum, S., Natural Connections: Perspectives in Community-Based Conservation, 1994. Island Press, Washington, DC.

Wimalaratana, W., Silva, D., 2009. Community Based Sustainable Tourism: A Case Study of the Monaragala District. Sri Lanka Jouranal of Agraian Studies 13 (1). 
Tables

Table 1: Spatial and Ecological Features with the range of total area of the Study Area

\begin{tabular}{lc}
\hline Feature & Area $\left(\mathrm{km}^{2}\right)$ \\
\hline River & 13.35 \\
High storied forest type & 17.98 \\
Low storied forest type & 20.90 \\
Shekher Bari & 0.54 \\
Kalir Mandir & 0.67 \\
Adachai Patrol Post & 1.27 \\
\hline Total & 54.71 \\
\hline
\end{tabular}

Table 2: Number of visitors to the Sundarbans West Forest Division

\begin{tabular}{cccc}
\hline Year & No. of local visitors & No. of foreign visitors & Revenue earned (BDT) \\
\hline $2007-2008$ & 11,521 & 132 & 561,520 \\
$2008-2009$ & 17,033 & 70 & $1,175,180$ \\
$2009-2010$ & 19,194 & 283 & $1,781,780$ \\
$2010-2011$ & 31176 & 213 & $1,810,450$ \\
$2011-2012$ & 42805 & 647 & $3,379,710$ \\
$2012-2013$ & 29103 & 520 & $6,726,040$ \\
$2013-2014$ & 24600 & 197 & $2,176,650$ \\
\hline
\end{tabular}

Source: Forest Department, Bangladesh

Table 3: Potential Impacts on Site Environment due to the Development of Ecotourism

\begin{tabular}{lcc}
\hline Will the site development cause the following: & Yes/No & Scale of Impacts \\
\hline - land disturbance or site clearance? & No & Low \\
- negative effects on rare (vulnerable), threatened or endangered species of flora or & No & Low \\
fauna or their habitat? & No & Low \\
- negative effects on designated wetlands? & No & Low \\
- spread of invasive plants or animals? & No & Low \\
- negative effects on wildlife habitat, populations, corridors or movement? & No & Low \\
- negative effects on locally important or valued ecosystems or vegetation? & No & Low \\
- destruction of trees and vegetation? & No & Low \\
- impact on fish migration and navigation? & No & Low \\
- obstruction of natural connection between river and wetlands inside project area & No & Low \\
or natural drainage system? & No & Low \\
- water logging due to inadequate drainage? & No & Low \\
- insufficient drainage leading to salinity intrusion? & No & Low \\
- negative effects on surface water quality, quantities or flow? & Low \\
- negative effects on groundwater quality, quantity or movement? & No & Low \\
- increased demand of water requirements leading to reduction of water supply for & No & Low \\
competing uses? & increase probability of spread of diseases and parasites? & Low
\end{tabular}


- loss of existing buildings, property, economic livelihood?

- negative impact on soil stability and compactness?

- impacts on sustainability of associated construction waste disposal?

- changes to the land due to material extraction?

- traffic disturbances due to construction material transport and wastes?

- increased noise due to transportation of equipment and construction materials?

- increased noise due to day-to-day construction activities?

- increased wind-blown dust from material (e.g. fine aggregate) storage areas?

- degradation or disturbance of historical or culturally important sites?

- health and safety issues?

Will the site development require the following:

- setting up of ancillary production facilities?

- significant demands on utilities and services?

- accommodation or service amenities to support the workforce during construction?

$\begin{array}{ll}\text { No } & \text { Low } \\ \text { No } & \text { Low } \\ \text { No } & \text { Low } \\ \text { No } & \text { Low } \\ \text { No } & \text { Low } \\ \text { No } & \text { Low } \\ \text { No } & \text { Low } \\ \text { No } & \text { Low } \\ \text { No } & \text { Low } \\ \text { No } & \text { Low }\end{array}$

Yes/No Scale of Impacts

No Low

Yes High

Yes Medium 
Figures:

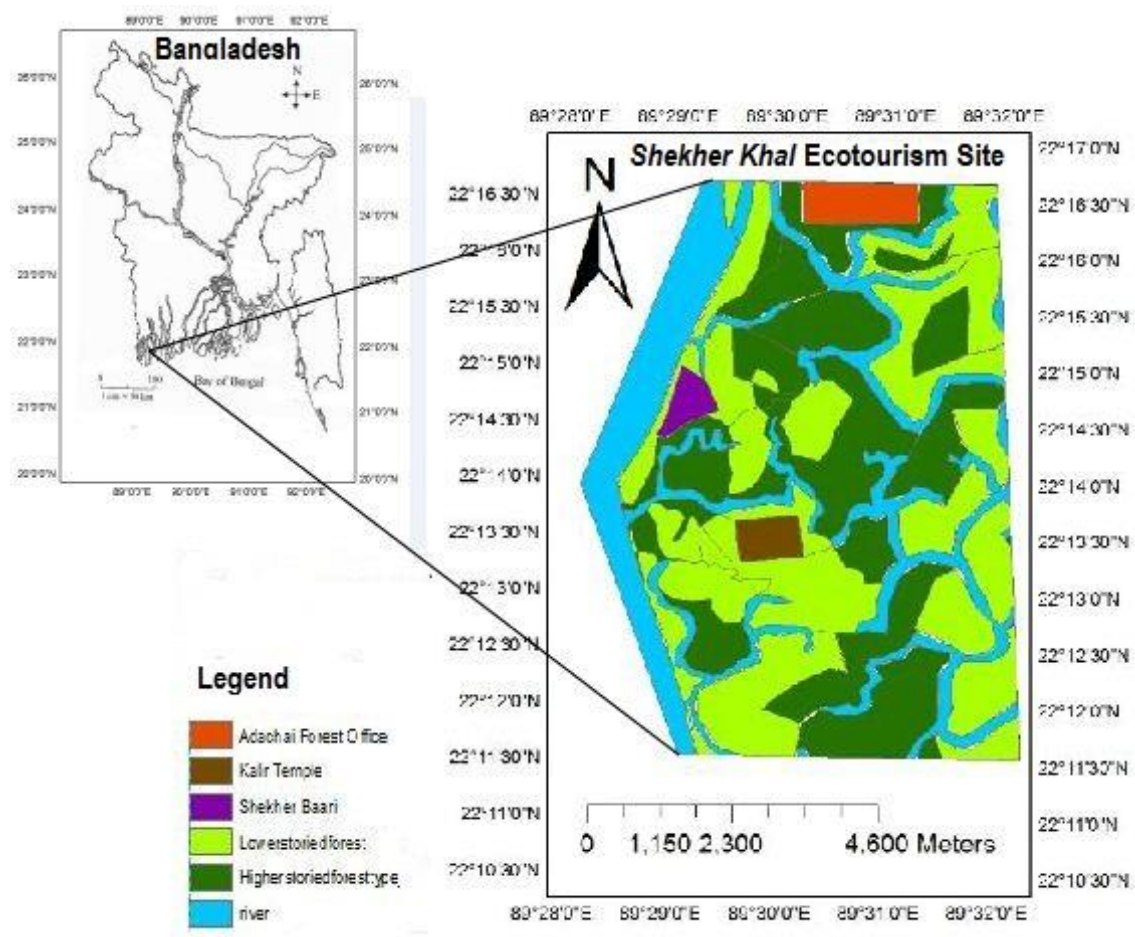

Figure 1: Location of the site - Shekher Khal
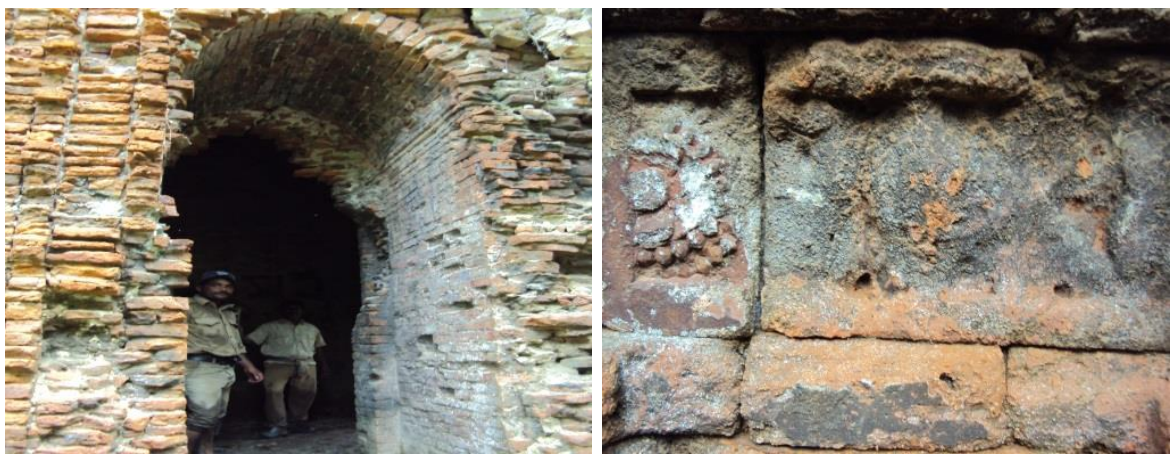

Figure 2: The entrance point of the ancient Kalir Mandir and the design of the ancient bricks
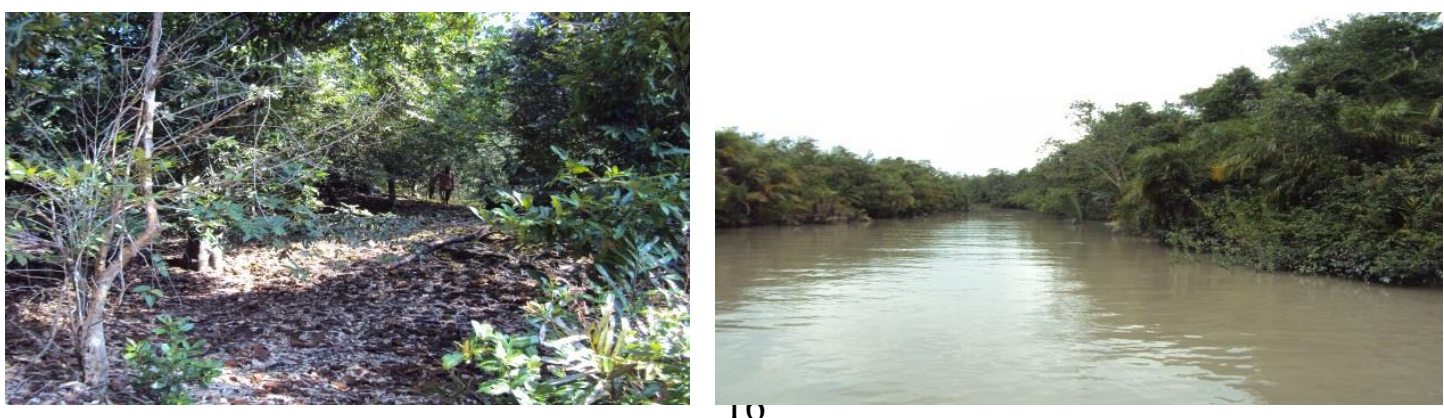
Figure 3: Shekher Bari on the bank of the river Shibsa and the Shekher Khal
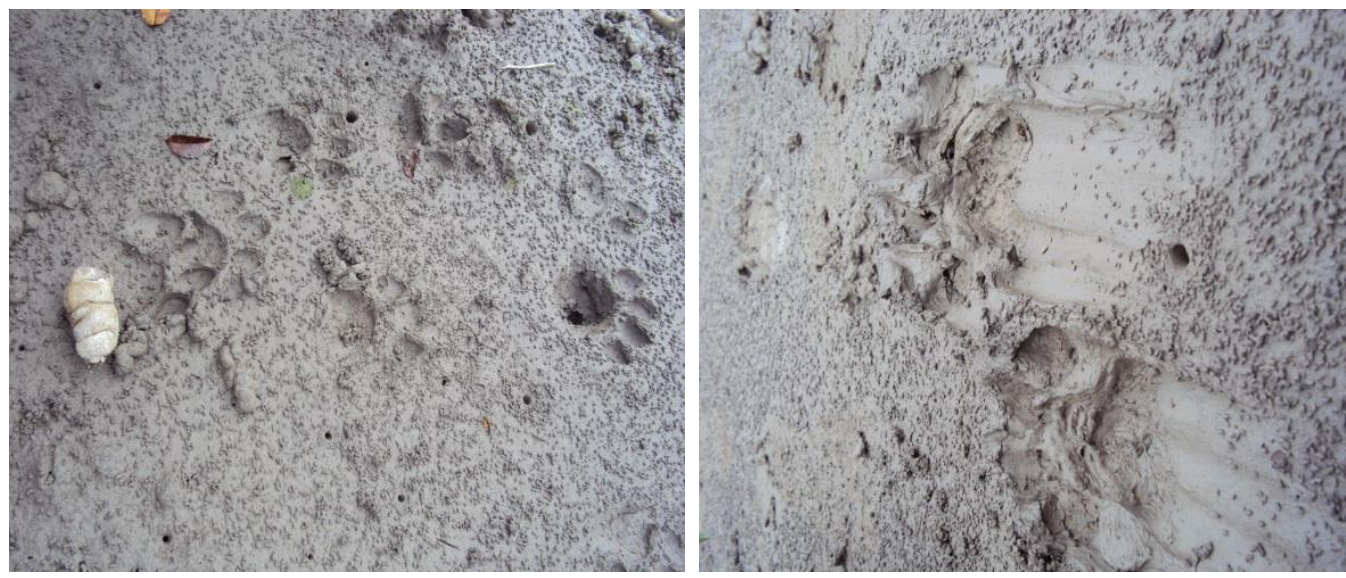

Figure 4: Pug marks of a couple of tigers at the temple site and pug marks while chasing preys 